\title{
Similarities between English and Chinese Emotional Metaphors
}

\author{
Guorui, Lv Yingli, Liu Yichu
}

Beijing City University, Beijing, 100083

Keywords: Emotion Metaphor; Conceptual Metaphor; Similarity.

\begin{abstract}
The theory of Conceptual Metaphor was proposed in the book of Metaphors We Live By which was created by Lakoff and Johnson. This theory thinks that conceptual metaphor is a concept expressed in metaphorical form. Metaphor is not only the problem of language, but also the way of thinking. Emotion is an abstract and complex concept, which is expressed frequently by metaphor. There are a lot of emotional metaphors in both English and Chinese languages. So, there are some similarities between English and Chinese emotional metaphor because human has the same physiological characteristics and emotional experience.
\end{abstract}

\section{Introduction}

People have already realized that metaphor plays a significant role in human communication and cognitive activities for a long time. The study of metaphor has never been interrupted. With time going by, metaphor has gradually transformed from the research object of traditional rhetoric to the object of many other subjects such as linguistics, philosophy, pragmatics, semantics, psychology, literary criticism, cognitive science, psychological analysis, linguistic psychology, translation, semiotics, and foreign language teaching.

In 1980, Lakoff and Johnson put forward a theory of metaphorical concept which was quite different from the traditional concept of metaphor in their book Metaphors we live by. This theory thinks that conceptual metaphor is a concept expressed in metaphorical form. Metaphor is not only the problem of language, but also the way of thinking. There is no denying that conceptual systems which people rely on for thinking and behavior are constructed and defined in a metaphorical way. Structurally, the function of metaphor is conceptualizing source domain to target domain. It is noteworthy that conceptual metaphors are deep while metaphorical expressions are shallow. A conceptual metaphor has multiple metaphorical expressions, and metaphorical expressions are dominated by conceptual metaphors.

In this book, Lakoff divides the conceptual metaphor into three categories as following: Structural Metaphor, Orientational Metaphor; Ontological Metaphor. Structural metaphor refers to the construction of one concept through another concept. That is superposition of two concepts. The words in all aspects of one concept are used to talk about another concept, and then the polysemous word is produced. Orientational Metaphor refers to the spontaneous organization of spatial orientation which is based on reference to the upper and lower, inside, outside, front and back, depth, center, edge in the same conceptual system. The perception of spatial orientation of is a basic ability of human. So, people understand the abstract state of emotion through the basic concepts derived from these basic experiences. Ontological Metaphor means that we can think the abstract and vague ideas, emotions, mental activities, events, state and other intangible concepts as concrete and tangible entities, especially the human body. According to the concept of orientational metaphor and ontological metaphor, the abstract emotion can be expressed by metaphor with the reference of spatial orientation or specific tangible entities as a cognitive mechanism, especially the human body itself. The research by Lakoff shows that the cognitive system of human is a metaphorical structure system. Metaphor is not only the decoration of language, but also the basic way of thinking and understanding the world. Nowadays, we find that metaphor is not only written by a writer, bus also common in daily speech of ordinary people through modern metaphorical view.

The so-called emotion refers to a psychological response to external stimuli, which involving feelings, physiology, behavior, experience, cognition and conceptualization. Most of the emotions 
come from the cognitive interpretation, and the construct of emotion is repeat and deepen of human's cognition, which make people feel a certain sense of things then make certain reactions. Emotion can be expressed by the means of nonverbal communication such as facial expression, eyes, gestures and body movements, and it also can be expressed abstractly by implicit language. While the language communication means to express emotions include emotional expression, exclamatory expression and emotional metaphor. We all know that people always use metaphors to express emotions in daily life, and we divide metaphors into emotional simile and metaphor. The feelings of people are rich and colorful, such as likes, anger, sadness, fear, admiration, disgust, etc. However, there is a problem that these feelings are abstract and difficult to express. Therefore, in order to depict the human's abstract emotion vividly, people always adopt metaphorizing. Many linguists have done a lot of research on emotional metaphors, and research shows that people's abstract emotion is largely expressed by metaphor which based on human perception. Some linguists have made a comparative analysis between English and Chinese emotional metaphors. And these researches show that there exist some similar conceptual metaphors in English and Chinese. In this paper, we take the English and Chinese daily language as research object. And we mainly analyze the cognitive similarities between English and Chinese emotional metaphors from two aspects of orientation metaphor and ontological metaphor and try to explore the origin of these emotional metaphors.

\section{Orientational Metaphor}

Lakoff points out that none of locality always can be used to express conceptual metaphors such as up and down (high and low) in English. These orientational metaphors are often used to express people's emotions. More specifically, joy and happiness can be replaced by up or high, and sadness can be replaced by down or low. Based on the orientational metaphor, we know that people use the concrete concepts of up-down, high-low, and center-periphery to describe the abstract concepts such as emotion, quantity and status. The conceptual metaphors of "happy is up, sad is down" are exist in English. And Chinese is similar to English in this respect.

Orientational Metaphor refers to the spontaneous organization of spatial orientation which is based on reference to the upper and lower, inside, outside, front and back, depth, center, edge in the same conceptual system. The perception of spatial orientation of is a basic ability of human. These orientational metaphors mentioned above are evidential rather than arbitrary, and the origination of them are the experience of basic spatial orientation of human body. These orientational metaphors are often used to express people's emotions. More specifically, joy and happiness can be replaced by up or high, and sadness can be replaced by down or low. As lift up one's head as example that the verb-lift up represents an upward trend and action to express human's joy. Through this example, we can know that the abstract behavior of pleasure s derived from the azimuth word of up. This is a common feature in English and Chinese, such as we can use the word high to describe "she has a high interest". Psychologists believe that emotion is vertical and downward movement in human body, joy is upward, and this upward impulse is more intense in children. According to the description of psychologist Tomkins, your lips extend outward and shoulders rise when you feel happy. What is more, your emotion upward to the head when you are anger. Sadness is downwards when emotions move vertically in the body. Through this, Darwin sums up the face of sadness as two features: one is the corner of mouth, and the other is the downward tilt of eyebrows. This is a general rule that the movement of emotion in the body can be regarded as a vertical flow up and down . Therefore, the behavior of human being tends is associated with positive emotions such as

"joy and happiness"; The downward orientation concept is mostly associated with negative emotions such as "sadness and despair". So, it's a natural thing to use orientational metaphor in emotional metaphors.

\section{Ontological Metaphor}

Ontological Metaphor means that we can think the abstract and vague ideas, emotions, mental 
activities, events, state and other intangible concepts as concrete and tangible entities, especially the human body. The most typical and representative metaphor is container metaphor. Human beings are independent from entities, so we can take person as a container which can divide inside and outside by body. People use this concept to describe other objects outside the body, such as houses, jungles, fields, areas and even some invisible, abstract time, behavior, activity, and state as a container. Containers not only refer to the human body, but also all organs in the body such as heart, liver, lungs, etc.

Kovecses (1990) points out that there is a common metaphor and metonymy principle in English that is the special physiological changes of the human body in a certain mood. And we also find the same principle in Chinese. In the analysis, it is found that specific emotional changes are associated with changes in a certain body of the body in terms of human physiological changes, especially the change of heart.

There exist many similarities between English and Chinese metaphors, which express specific emotional changes from the above examples. These metaphorical expressions are expressions of joy, sadness, fear and anger with the help of physiological changes in human emotions. The change of people's emotion is complex and changeable, and difficult to describe abstract thing at the same time. People understand emotional changes are depend on concrete physical entities. Such as we use Have one's heart in one's boots to describe in English, while we use shudder with fear in Chinese. The emotion of fear is unspeakable, but it often has a close relationship with the change of specific things, especially the rapid beating of "heart". Thus it can be seen that the abstract fear emotion is expressed by the tangible entity - the beating of the heart. It also shows that the entity metaphor plays a very important role in the understanding of people's emotional change. We can consider the abstract and vague concepts of thought, emotion, mental activity, and state as concrete, tangible entities, especially by means of the corresponding changes in a particular organ of the body. The special changes in the visible, tangible and tangible entities of the liver and lungs are used to describe the change of abstract emotion in the above examples.

In addition to using the physiological changes to express emotions by English and Chinese, there always exist the change of behavior to express emotion. English and Chinese often use specific changes of human behavior to describe human emotions. However, the choice of metaphor in emotional metaphors is not arbitrary but has certain rules. It largely influenced and restricted by human physiological factors. For example, people feel cold when they are afraid or fear; people tend to open their mouths involuntarily when they are surprised; People's body temperature and pressure rises when they are angry; people want to dance when they are happy. The changes of human behavior are tangible and concrete, such as jumping, laughing, singing, glaring, tears, etc. As the case mentioned above, this concrete behavior change often involves metaphorical emotional changes. For example, people often use "eyebrows locked", "Sob one' s heart out" when we describe "sadness". When person meet a sad thing, a physical instinct is crumple to his eyebrows, think hard, or weep, tears, tears, tears, or tears. Although the emotional changes of sadness are intangible, abstract and indescribable, people can use the concrete physical behavior to express their sadness. It can be seen that tangible concrete entities can fully and effectively represent metaphorical and abstract emotional changes.

Container metaphor is a typical ontological metaphor. This physical basis of metaphor is so obvious that and physical space has boundary or conceives the boundary is a container, such as the human body, the house, the jungle, the field, the area, and even some invisible, abstract events, actions, activities, and states all can be considered as a container. As we all know that emotion is an abstract condition. The body of the emotional experience is a container which has the internal and external points, and the skin is separated from the outside as an interface. When people experiencing emotion, the blood circulation will undergo certain changes, and the circulation will accelerate or slow down. When people consider the container concept to the abstract domain of emotion, then the metaphorical concept of "emotion is the liquid in the container" is produced. In addition, Chinese also has the metaphorical concept of "anger is the gas in the container". From the above English examples and Chinese translation, we can see that English and Chinese both use the 
liquid in the container to metaphorical emotion. But only Chinese think "heart" as a container, which Chinese ancients thought the physiological basis of the "the seven human emotions" was the first of the five internal organs-the origin of the heart. We can see that emotion likes the water in container are "thick" and "light”, "deep" and "shallow"; While the mood of people is smooth like water, and it is "undulating” when it "calm”. For example: we use "ups and downs", "anger surged with in him" when describe a person's emotional agitation. It is also a common experience of human life to observe metaphorical emotions through the observation of two languages. The emotional or angry emotions of human beings are complex, intangible, abstract, and difficult to understand, but people tend to use simple, tangible, specific, well known liquids in the entities or containers to express the complex image of human emotions. Language can reflect the objective world. By observing, we find that the languages of English and Chinese can use one of the names of objective substances - liquid to metaphoric feelings, which is the common experience of people's life.

\section{Conclusion}

We find that there are many commonalities in emotional expression between English and Chinese through the analysis of emotional expressions in a large number of daily expressions. The common expression of emotional metaphor derives from our life experience, and the human experience of emotion is largely due to the common physiological and psychological effects of emotion on the body. Either the conceptual metaphor proposed by Lakoff or the root analogy studied by Goaltly shows that the metaphor is far more than a rhetorical device, which profoundly affects or even part of our conceptual system. The concept is the way of thinking that reflects the key characteristics and essential attributes of objective things. It is the product of human understanding of the objective world and is formed through a large number of human beings' long-term and practical activities. Through the commonness of English and Chinese emotional metaphors, it is found that the emotional metaphor is essentially metaphor as a cognitive mechanism, reference to spatial orientation, or a concrete physical entity, especially the human body itself. Therefore, it can be said that emotional metaphor is not only the mechanism of emotional cognition, but also the result of emotional cognition.

\section{References}

[1] Goatly, A. The language of metaphors [M] London \& New York: Routledge, 1997.

[2] Kovecses, Zoltan and Peter Szabo. Idioms: A view from cognitive semantics.

[3] Lakoff, G. \& Johnson. Metaphors we live by [M]. Chicago: University of Chicago Press, 1980.

[4] [British] Sean Holden. Psychological and Emotional Emergency [M]. Weijuan Zhang (Translate), Beijing University of Aeronautics and Astronautics Press, 1991.

[5] Wencui Chen. Studies on the Conceptions of Emotional Expressions as Viewed from a Cognitive Perspective [J]. Journal of University of Nanhua, 2003.

[6] Yaoyong Qin. A Comparison of Cognitive Metaphors between English and Chinese [J]. Journal of Yulin Teachers College, 2002, (2).

[7] Jinxing Shu, Yujuan Xu. To View Emotional Metaphor from Metaphorical Cognition [J]. Zhengzhou, Journal of University of Science and Technology of Henan, 2003.

[8] Min Zhang. Cognitive Linguistics and Chinese Noun Phrases [M]. China Social Sciences Press, 1998.

[9] Yanfang Zhao. Metaphorical Cognitive Structure of Language-A Metaphorical Evaluation of Our Existence [J]. Foreign Language Teaching and Research, 1995, (3): 67-72. 